\title{
Three new lengths for cyclic Legendre pairs
}

\author{
N. A. Balonina, Dr. Sc., Tech., Professor, orcid.org/0000-0001-7338-4920, korbendfs@mail.ru \\ D. Ž. Đokovic ${ }^{6}$, Dr. Sc., Tech., Distinguished Professor Emeritus, orcid.org/0000-0002-0176-2395, \\ djokovic@uwaterloo.ca \\ aSaint-Petersburg State University of Aerospace Instrumentation, 67, B. Morskaia St., 190000, \\ Saint-Petersburg, Russian Federation \\ bUniversity of Waterloo, Department of Pure Mathematics and Institute for Quantum Computing, Waterloo, \\ Ontario, N2L 3G1, Canada
}

\begin{abstract}
Introduction: It is conjectured that the cyclic Legendre pairs of odd lengths > 1 always exist. Such a pair consists of two functions $a, b: G \rightarrow Z$, whose values are +1 or -1 , and whose periodic autocorrelation functions add up to the constant value -2 (except at the origin). Here $G$ is a finite cyclic group and $Z$ is the ring of integers. These conditions are fundamental and the closely related structure of Hadamard matrices having a two circulant core and double border is incompletely described in literature, which makes its study especially relevant. Purpose: To describe the two-border two-circulant-core construction for Legendre pairs having three new lengths. Results: To construct new Legendre pairs we use the subsets $X=\{x \in G: a(x)=-1\}$ and $Y=\{x \in G$ : $b(x)=-1\}$ of $G$. There are 20 odd integers $v$ less than 200 for which the existence of Legendre pairs of length $v$ is undecided. The smallest among them is $v=77$. We have constructed Legendre pairs of lengths 91,93 and 123 reducing thereby the number of undecided cases to 17. Some new examples of cyclic Legendre pairs for lengths $v \leq 123$ are given. Practical relevance: Hadamard matrices are used extensively in the problems of error-free coding, and compression and masking of video information. Programs for search of Hadamard matrices and a library of constructed matrices are used in the mathematical network "mathscinet.ru" together with executable on-line algorithms.
\end{abstract}

Keywords - Hadamard matrices, periodic autocorrelation functions, Legendre pairs, cyclic matrices, double-border twocirculant-core construction.

For citation: Balonin N. A., Đoković D. Ž. Three new lengths for cyclic Legendre pairs. Informatsionno-upravliaiushchie sistemy [Information and Control Systems], 2021, no. 1, pp. 2-7. doi:10.31799/1684-8853-2021-1-2-7

\section{Introduction}

It is conjectured that the cyclic Legendre pairs of odd lengths $>1$ always exist. See the next section for the definition of the Legendre pairs and Legendre difference families (DF). It is known that they exist for odd lengths $v$ in the range $2<v<76$. The smallest unresolved case is $v=77$. According to [1], there are four series of known cyclic Legendre pairs of odd length $v>1$ (the first three are infinite):

(i) $v$ is a prime number;

(ii) $2 v+1$ is a power of a prime number;

(iii) $v+1$ is a power of 2 ;

(iv) $v=p q$, where $p$ and $q$ are prime numbers and $q-p=2$.

We refer to (i) as the classical series because the construction is based on the sequence of the classical Legendre symbols [1]. The case (ii) is the Szekeres series provided by the well known series of so called Szekeres difference sets (in fact they are difference families) [2, 3]. The series (iii) is known as the Galois series [4] and (iv) is the twin-prime series, see e. g. [5, Theorem 9.4].

The series (iii) and (iv) as well as (i) for $v \equiv 3(\bmod 4)$ are obtained from the three well known series of difference sets having the parameters $(v ;(v-1) / 2 ;(v-3) / 4)$. We refer to such Legendre pairs as type 1 (see next sections).
If we start with the list of odd integers $v$ in the range $76<v<200$ and remove those which satisfy at least one of the conditions (i)-(iv) above we obtain the list of 20 integers:

$77,85,87,91,93,115,117,123,129,133,145$, 147, 159, 161, 169, 175, 177, 185, 187, 195.

This is in fact the list of all cases with $v<200$ for which the question of existence of cyclic Legendre pairs is unresolved.

In the paper [1, p. 80] the authors list 22 odd lengths $<200$ for which they assert that the existence question of cyclic Legendre pairs is unresolved. However, the lengths 121 and 171 should not have been included in that list since $2 \cdot 121+1=243=3^{5}$ and $2 \cdot 171+1=343=7^{3}$ are prime powers. (On the other hand according to $[6$, sec. 4] the number 57 should have been included.)

There are two other series of Legendre DFs in elementary abelian groups which include some cyclic cases. One of them appears in [7] and the other in [8, Theorem 3.1]. However, while they provide new cyclic Legendre DFs they do not give new lengths $v$ in the cyclic case.

Our main result is in section with new pairs, where we give the first examples of cyclic Legendre pairs of lengths 91,93 and 123. Thereby we reduce to 17 the number of the undecided cases listed above. 
According to [1], exhaustive computer searches for cyclic Legendre pairs where carried out for all odd $v<48$. We consider the odd integers $v$ in the range $48<v<76$ and we list the new cyclic Legendre DFs of type 2 that we constructed. Only for $v=69$ and $v=75$ we failed to find any new pairs.

\section{Notation and definitions}

Let $G$ be a finite abelian group (written additively) and let $v$ denote its order. For any function $f: G \rightarrow \mathbf{R}$ its periodic auto-correlation function, $\mathrm{PAF}_{f}: G \rightarrow \mathbf{R}$, is defined by the formula $\mathrm{PAF}_{f}(s)=$ $=\sum_{x \in G} f(x) f(x+s)$. We refer to $s$ as the shift variable.

Definition 1. We say that an ordered pair of functions $(f, g)$ mapping $G \rightarrow\{+1,-1\}$ is a Legendre pair on $G$ if $\operatorname{PAF}_{f}(s)+\operatorname{PAF}_{g}(s)=-2$ for all nonzero shifts $s$. (For $s=0$ we have $\operatorname{PAF}_{f}(0)=\operatorname{PAF}_{g}(0)=v$.)

For any function $f: G \rightarrow\{+1,-1\}$ we $\operatorname{set} G_{f}=\{\mathrm{x} \in G$ : $f(x)=-1\}$.

Proposition. An ordered pair of functions ( $f$, g): $G \rightarrow\{+1,-1\}$ is a Legendre pair on $G$ if and only if $\left(G_{f}, G_{g}\right)$ is a difference family in $G$ with parameters $\left(v, k_{1}, k_{2}, \lambda\right)$ where $k_{1}=\left|G_{f}\right|, k_{2}=\left|G_{g}\right|$ and $\lambda=k_{1}+k_{2}-(v+1) / 2$. In particular the existence of Legendre pairs on $G$ implies that v must be odd.

Proof: This follows immediately from Theorems 3 and 4 of [9].

Remark. It is customary to require that the length $v$ of a Legendre pair is $>1$. However, according to the above definition, if $G$ is a trivial group then any pair of functions $G \rightarrow\{+1,-1\}$ is a Legendre pair. The condition in the definition holds by default (there are no nonzero shifts).

If we introduce the additional parameter $n=k_{1}+k_{2}-\lambda$ then we have $v=2 n-1$. By using the well known equation $k_{1}\left(k_{1}-1\right)+k_{2}\left(k_{2}-1\right)=$ $=\lambda(v-1)$ one can easily show that

$$
\left\{k_{1}, k_{2}\right\} \subseteq\left\{\frac{v-1}{2}, \frac{v+1}{2}\right\} .
$$

In view of the above proposition, we shall refer to the difference families $(X, Y)$ in $G$ having the parameters $\left(v ; k_{1}, k_{2} ; \lambda\right)$ with $v=2 n-1$ as Legendre DFs.

We say that a Legendre pair on a group $G$ is $c y$ clic if the group $G$ is cyclic. In this note we deal only with the cyclic Legendre pairs and we may assume that $G=\mathbf{Z}_{v}$, the additive group of integers modulo $v$.

We give a simple example to introduce the notation that we will use in the rest of this note.

Example: $v=39$. In this example $v=13 \cdot 3$ and so $\mathbf{Z}_{v}^{*}$ (the group of units of the ring $\mathbf{Z}_{v}$ ) is isomorphic

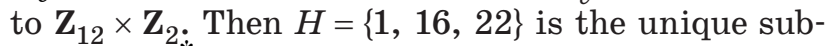
group of $\mathbf{Z}_{v}^{*}$ of order 3 . There exists an $H$-invariant
Legendre DF with parameter set $(39 ; 19,19 ; 18)$, namely

$$
\begin{aligned}
& X=H\{0,1,2,3,4,12,14\} \\
& Y=H\{0,2,3,4,8,14,19\}
\end{aligned}
$$

In general, if $H$ is a subgroup of $\mathbf{Z}_{v}^{*}$ and $S$ a subset of $\mathbf{Z}_{v}$ then the product $H S$ is defined to be $H S=\{h s(\bmod v): h \in H, s \in S\}$. Note that $H\{0\}=$ $=\{0\}$.

\section{Cyclic Legendre pairs of new lengths $v=91,93,123$}

We have constructed four pairwise nonequivalent Legendre DFs $\left(X_{i}, Y_{i}\right)$ of length 91 . For the definition of equivalence see the latest section of the paper. Only one DF is constructed for each of the lengths 93 and 123. Instead of Legendre pairs, we list the corresponding difference families. In each case, each block is a union of orbits of a fixed subgroup $\left(H, H_{1}\right.$ or $\left.H_{2}\right)$ of order 3 or 5 of $\mathbf{Z}_{v}^{*}$.

$$
v=91
$$

Four pairwise nonequivalent Legendre DFs: $(91 ; 45,45 ; 44) H_{1}=\{1,16,74\}, H_{2}=\{1,9,81\}$ $X_{1}=H_{1}\{1,2,7,14,15,17,19,22,25,28,38,43$, $44,50,55\}$

$Y_{1}=H_{1}\{2,3,10,11,14,17,20,22,28,43,44,45$, $49,50,55\}$

$X_{2}=H_{1}\{1,4,5,8,9,11,15,22,27,28,34,38$, $43,49,50\}$

$Y_{2}=H_{1}\{8,9,10,11,14,17,22,25,28,33,34,38$, $44,50,55\}$

$X_{3}=H_{1}\{2,3,5,9,10,14,15,20,27,28,33,34$, $38,50,55\}$

$Y_{3}=H_{1}\{3,4,11,14,19,25,27,28,33,34,43,44$, $45,50,55\}$

$X_{4}=H_{2}\{2,5,14,16,19,20,23,24,29,30,37,40$, $46,48,49\}$

$Y_{4}=H_{2}\{2,4,6,8,13,14,16,23,30,37,38,39$, $40,46,49\}$

$$
v=93
$$

Only one Legendre DF:

$(93 ; 46,46$; 45) $H=\{1,25,67\}$

$X=H\{0,1,2,3,5,8,10,12,13,16,22,24,43$, $44,47,48\}$

$Y=H\{0,1,3,4,5,9,11,12,18,20,22,37,40$, $43,44,51\}$

Only one Legendre DF:

$$
v=123
$$

$(123 ; 61,61 ; 60) H=\{1,10,16,37,100\}$

$X=H\{0,1,3,6,11,13,28,29,33,35,43,45,59\}$

$Y=H\{4,5,6,11,14,15,18,19,22,28,33,41$, $45\}$ 


\section{Type 1 and type 2}

Let $(X, Y)$ be a Legendre $\mathrm{DF}$ in $\mathbf{Z}_{v}$. It is easy to see that if $X$ is a difference set then $Y$ must be a difference set too. In that case we say that $(X, Y)$ (and its corresponding Legendre pair) is of type 1 , and otherwise that it is of type 2. The Legendre pairs in the Galois and the twin-prime series as well as those in the classical series with $v$ a prime number $\equiv 3(\bmod 4)$ are of type 1 . Note that two equivalent Legendre DFs must have the same type. Hence the study of type 1 Legendre DFs essentially reduces to the study of difference sets. For that reason we shall consider only the Legendre DFs of type 2.

As mentioned earlier, it is conjectured that cyclic Legendre DFs exist for all odd lengths $v>2$. We propose a bit stronger version.

Conjecture. Legendre DFs of type 2 exist for all odd lengths $v>8$.

One of the objectives of this note is to verify this conjecture for $v<76$. It follows from [1] that the conjecture is true for $v<48$. If $v$ is a prime number $\equiv 1(\bmod 4)$ then the classical Legendre pair of length $v$ is of type 2. One can verify that the Legendre pairs in the Szekeres series having length $v$ in the interval $4<v<76$ are of type 2 . Thus, in order to verify the above conjecture for $v<76$ it suffices to verify it in the cases $v=49$, $55,57,59,67,71$. This will be done in the next section.

We do not know whether all Legendre pairs of length $v>4$ in the Szekeres series are of type 2 .

\section{New Legendre DFs of type 2}

We list the cyclic Legendre DFs of type 2 and length $v>48$ that we have constructed here. We imposed the restriction $v>48$ because for $v<48$ exhaustive searches have been carried out [1].

$$
v=49
$$

The Legendre DF below is not equivalent to the one in [1, p. 85]:

$(49 ; 24,24 ; 23) H=\{1,18,30\}$

$X=H\{1,2,8,9,13,24,26,29\}$

$Y=H\{2,3,4,6,7,8,12,37\}$

$$
v=51
$$

The two Legendre DFs below together with the one in $[1$, p. 85] and another one from the Szekeres series are pairwise nonequivalent:

$(51 ; 25,25 ; 24) H=\{1,16\}$

$X_{1}=H\{0,1,2,4,6,8,19,24,25,28,35,38,41\}$

$Y_{1}=H\{0,2,4,5,9,14,15,18,21,22,25,31,35\}$ 41\}

$X_{2}=H\{1,2,9,11,17,18,19,21,24,25,28,38$,

$Y_{2}=H\{1,3,4,5,8,9,15,17,18,19,21,22,31\}$

$$
v=53
$$

All ten Legendre DFs listed below are pairwise nonequivalent. The first five are known: the first belongs to the classical series, the second is from [7], the third from [8], the fourth from the Szekeres series, and the fifth from [1, p. 85]. We have constructed many Legendre DFs for $v=53$ but we recorded only five of them (the last five in the list below):

$(53 ; 26,26 ; 25) H=\{1,10,13,15,16,24,28,36$, $42,44,46,47,49\}$

$$
\begin{aligned}
& X_{1}=H\{1,4\}, Y_{1}=H\{2,5\} \\
& X_{2}=H\{1,2\}, Y_{2}=H\{1,5\} \\
& X_{3}=H\{1,2\}, Y_{3}=H\{2,5\}
\end{aligned}
$$

$X_{4}=\{1,4,5,6,8,14,16,17,19,21,22,23,26$, $28,29,33,35,38,40,41,42,43,44,46,50,51\}$

$Y_{4}=\{4,8,9,10,12,14,15,18,19,21,22,23,24$, $29,30,31,32,34,35,38,39,41,43,44,45,49\}$ $X_{5}=\{5,7,12,13,15,18,19,24,26,28,30,33$, $35,36,37,38,39,42,43,44,46,47,48,50,51,52\}$ $Y_{5}=\{4,7,8,10,11,14,15,20,21,23,24,25,26$, $29,30,32,37,40,42,44,47,48,49,50,51,52\}$ $X_{6}=\{0,1,2,3,5,9,10,11,12,14,17,24,25,26$, $28,29,34,35,40,44,45,46,47,48,50,51\}$ $Y_{6}=\{0,2,4,6,7,8,12,14,17,19,20,21,22,24$, $27,28,30,31,34,35,40,44,46,48,49,52\}$ $X_{7}=\{0,2,3,4,7,10,11,12,13,16,17,18,21$, $23,32,33,37,38,39,40,41,42,45,49,50,52\}$ $Y_{7}=\{0,1,3,6,7,12,13,15,20,21,23,24,25$, $31,33,35,37,38,40,42,44,46,47,48,50,51\}$ $X_{8}=\{0,1,2,6,7,9,12,13,14,15,18,19,20,24$, $34,36,37,38,39,41,43,45,46,49,51,52\}$ $Y_{8}=\{0,1,5,8,9,11,12,15,16,20,21,23,24$, $25,31,33,35,38,40,41,43,44,47,49,51,52\}$ $X_{9}=\{0,6,8,9,10,12,14,15,23,26,28,30,31$, $32,33,36,37,38,40,41,42,43,48,49,50,52\}$ $Y_{9}=\{0,1,2,3,6,8,10,11,14,15,16,18,20,23$, $29,31,34,35,38,39,41,42,45,47,48,52\}$ $X_{10}=\{0,1,6,7,8,13,14,15,17,18,19,21,22$, $23,24,26,28,32,37,38,40,46,48,49,50,51\}$ $Y_{10}=\{0,2,6,7,10,13,14,15,16,18,19,21,22$, $25,26,30,31,32,33,34,36,40,43,46,48,50\}$

$$
v=55
$$

The Legendre DF below is not equivalent to the one listed in [1, p. 85]:

$(55 ; 27,27 ; 26) H=\{1,34\}$

$X=H\{1,2,6,7,8,9,10,11,15,16,21,24,27$, $37,50\}$

$Y=H\{1,2,3,8,16,17,19,20,21,25,27,29,37$, $40,42\}$

$$
v=57
$$

In this case only two nonequivalent Legendre DFs are known. The first one was constructed in 2007 [6] and the second one constructed very recently in [10, Section 2.4]. We have constructed the six Legendre DFs below. The first five of them, 
together with the two known DFs, are pairwise nonequivalent. The sixth is equivalent to the one constructed in [10]:

(57; 28, 28; 27) $H=\{1,7,49\}$

$X_{1}=H\{0,2,3,4,8,16,23,24,30,31\}$

$Y_{1}=H\{0,2,3,4,6,8,16,23,24,29\}$

$X_{2}=H\{0,2,8,10,12,23,24,29,30,31\}$

$Y_{2}=H\{0,3,4,5,6,22,23,24,29,31\}$

$X_{3}=H\{0,1,3,5,6,10,16,23,29,30\}$

$Y_{3}=H\{0,1,2,3,15,16,22,24,29,31\}$

$X_{4}=H\{0,1,2,4,6,11,15,29,30,31\}$

$Y_{4}=H\{0,8,11,12,22,23,24,29,30,31\}$

$X_{5}=H\{0,2,3,4,6,10,15,16,29,31\}$

$Y_{5}=H\{0,1,3,8,10,15,16,23,24,29\}$

$X_{6}=H\{0,2,3,4,5,11,15,16,22,30\}$

$Y_{6}=H\{0,1,2,4,15,16,22,23,24,30\}$

$$
v=59
$$

First examples of Legendre DFs of length 59 and type 2:

$(59 ; 29,29 ; 28)$

$X_{1}=\{0,1,2,3,4,5,6,10,12,13,15,16,19,20$, $21,25,27,30,31,33,37,38,39,41,43,44,45,52$, $56\}$

$Y_{1}=\{0,1,3,4,5,6,7,10,12,13,14,15,17,18$, $20,23,26,27,28,30,34,35,36,39,43,45,48,50$, $55\}$

$X_{2}=\{0,1,2,3,4,5,7,8,9,10,12,15,16,17,22$, $24,25,26,28,29,33,34,38,39,42,44,48,50,53\}$ $Y_{2}=\{0,2,3,4,6,7,9,10,12,14,15,18,19,21$, $23,25,29,30,31,32,33,36,38,39,43,46,49,50$, 51\}

$X_{3}=\{0,1,2,3,4,5,7,8,9,10,14,16,19,20,21$, $24,27,28,30,32,36,37,38,41,45,47,48,51,54\}$

$Y_{3}=\{0,2,3,4,5,6,8,9,10,12,14,16,17,19$, $24,25,26,28,29,31,32,34,39,42,43,44,50,54$, $55\}$

$X_{4}=\{0,1,2,3,4,6,9,11,12,13,15,16,18,19$, $20,23,24,29,30,32,36,37,38,40,41,46,47,49$, $56\}$

$Y_{4}=\{0,1,2,4,6,7,9,10,11,13,14,15,17,21$, $22,25,26,28,30,31,33,35,36,41,43,45,46,47$, $53\}$

$X_{5}=\{0,1,2,3,4,6,10,12,13,14,16,18,19$, $21,23,26,27,28,29,31,32,36,37,40,42,43,44$, $49,51\}$

$Y_{5}=\{0,1,2,4,5,7,8,10,11,13,14,17,18,20$, $21,22,25,26,31,32,36,37,38,40,42,44,45,47$, $52\}$

$X_{6}=\{0,1,2,3,5,6,7,8,9,11,13,15,17,18,20$, $24,27,28,29,31,32,38,40,41,44,45,46,54,55\}$

$Y_{6}=\{0,1,2,3,6,7,9,10,12,13,15,17,19,20$, $21,24,25,27,31,32,33,36,40,41,43,44,46,49$, 51\}

$$
v=61
$$

In this case apart from the classical Legendre $\mathrm{DF}$ there is another one provided by a lemma of
J. Seberry Wallis [7], see also [11, Lemma 2]. The Legendre DF below is not equivalent to any of them:

$(61 ; 30,30 ; 29) H=\{1,9,20,34,58\}$

$X=H\{2,3,4,5,12,26\}$

$Y=H\{3,4,5,10,12,13\}$

$$
v=63
$$

The six new Legendre DFs below and the one from the Szekeres series are all pairwise nonequivalent:

$(63,31,31,30) H_{1}=\{1,4,16\}, H_{2}=\{1,25,58\}$, $H_{3}=\{1,8,11,23,25,58\} X_{1}=H_{1}\{2,3,6,10,11,22$, $23,30,31,42,47\}$

$Y_{1}=H_{1}\{1,2,7,9,10,11,14,15,21,31,47\}$

$X_{2}=H_{1}\{1,3,9,13,14,15,21,22,23,30,47\}$

$Y_{2}=H_{1}\{3,5,7,9,10,11,15,21,22,23,30\}$

$X_{3}=H_{1}\{1,2,3,6,9,11,14,21,22,30,31\}$

$Y_{3}=H_{1}\{1,2,3,6,7,9,11,15,22,42,47\}$

$X_{4}=H_{1}\{2,3,7,9,10,14,15,21,26,30,43\}$

$Y_{4}=H_{1}\{3,6,7,10,11,14,21,27,30,43,47\}$

$X_{5}=H_{2}\{1,3,6,7,15,17,20,27,29,40,42\}$

$Y_{5}=H_{2}\{3,5,7,8,10,15,17,21,27,30,40\}$

$X_{6}=H_{3}\{0,2,9,10,15,19,27\}$

$Y_{6}=H_{3}\{0,2,5,7,9,15,27\}$

$$
v=65
$$

The Legendre DF below is not equivalent to the one in the Szekeres series:

$(65 ; 32,32 ; 31) H=\{1,16,61\}$

$X=H\{1,5,6,9,18,20,22,23,24,26,35,52\}$

$Y=H\{0,1,3,7,11,13,19,22,23,24,36,50\}$

$$
v=67
$$

The following Legendre DF gives the first example of Legendre pairs of length 67 and type 2 :

$(67 ; 33,33 ; 32) H=\{1,29,37\}$

$X=H\{1,3,5,6,10,16,17,30,34,41,53\}$

$Y=H\{2,4,6,9,12,15,16,18,25,32,41\}$

$$
v=71
$$

We give the first example of a Legendre DF of length 71 and of type 2 :

$(71 ; 35,35 ; 34) H=\{1,5,25,54,57\}$

$X=H\{1,2,3,6,11,14,27\}$

$Y=H\{1,2,3,9,14,18,42\}$

$$
v=73
$$

The Legendre DF below is not equivalent to the one in the classical series:

$(73 ; 36,36$; 35) $H=\{1,8,64\}$

$X=H\{2,5,6,7,9,11,12,17,18,26,35,42\}$

$Y=H\{1,2,3,7,9,13,18,21,26,33,35,42\}$

$$
v=111
$$

The Legendre DF below is not equivalent to the one belonging to the Szekeres series:

$(111 ; 55,55 ; 54) H=\{1,10,100\}$ 
$X=H\{0,1,2,3,4,7,8,9,13,16,21,22,27,41$, $42,44,54,62,63\}$

$Y=H\{0,1,3,4,5,6,7,8,11,16,17,21,26,27$, $52,53,55,63,64\}$

$$
v=121
$$

Note that $2 v+1=243=3^{5}$ is a prime power $\equiv 3(\bmod 4)$. We list below two Legendre DFs $\left(X_{i}, Y_{i}\right)$, $i=1,2$. The first one is equivalent to the DF in the Szekeres series. The block $X_{1}$ is skew and $Y_{1}$ is symmetric. We have constructed the second Legendre DF $\left(X_{2}, Y_{2}\right)$ with $X_{2}=X_{1}$ and verified that the two DFs are nonequivalent. Although $Y_{2}$ is not symmetric, the second pair still qualifies as a Szekeres difference set according to [3, Definition 5.6]:

$(121 ; 60,60 ; 59) H=\{1,3,9,27,81\}$

$X_{1}=H\{4,10,11,20,25,26,34,35,38,40,67,76\}$

$Y_{1}=H\{1,7,8,10,16,20,26,31,35,38,61,94\}$

$X_{2}=X_{1}$

$Y_{2}=H\{1,4,5,8,11,13,17,20,22,26,34,76\}$

\section{Equivalence of Legendre pairs}

To define the equivalence, we need first to define the elementary transformations on the set of Legendre pairs on a given finite abelian group $G$ of odd order $v$. (We assume that $G$ is written additively.) If $f$ is a function $G \rightarrow\{+1,-1\}$ and $s \in G$ then we say that the function $G \rightarrow\{+1,-1\}$ sending $x \rightarrow f(s+x)$ is the translate of $f$ by $s$.

The elementary transformations of a Legendre pair $(f, g)$ are the following:

(i) interchange $f$ and $g$;

(ii) replace $f$ by $-f$;

(iii) replace $f$ by its translate by $s \in G$; (iv) replace $f$ by $f \circ \mathrm{l}$, where $\mathrm{l}$ is the automorphism of $G$ sending each $x \in G$ to its inverse $-x$;

(v) replace $(f ; g)$ by $(f \circ \alpha, g \circ \alpha)$, where $\alpha$ is an automorphism of $G$.

Definition 2. We say that two Legendre pairs on $G$ are equivalent if one can be transformed to the other by performing a finite sequence of elementary transformations.

The effect on $\left(G_{f}, G_{g}\right)$ of the above elementary transformations is as follows:

(i)' interchange $G_{f}$ and $G_{g}$;

(ii)' replace $G_{f}$ by $G \backslash G_{f}$;

(iii)' replace $G_{f}$ by the translate $G_{f}-s$;

(iv)' replace $G_{f}$ by $-G_{f}$;

(v)' replace $\left(G_{f}, G_{g}\right)$ by $\left(\alpha^{-1}\left(G_{f}\right), \alpha^{-1}\left(G_{g}\right)\right)$.

We define the equivalence of Legendre DFs on $G$ by using the (i)'-(v)' as elementary transformations of pairs $\left(G_{f}, G_{g}\right)$. Then two Legendre pairs are equivalent if and only if their Legendre DFs are equivalent. We remark that because of (ii)', two equivalent Legendre DFs may have different parameter sets.

\section{Financial support and acknowledgements}

The research of the first author leading to these results has received financial support of the Ministry of Science and Higher Education of the Russian Federation, agreement No FSRF-2020-0004. The research of the second author was enabled in part by support provided by SHARCNET (http://www. sharcnet.ca) and Compute Canada (http://www. computecanada.ca).

The authors wish to sincerely thank Tamara Balonina for converting this note into printing format.

\section{References}

1. Fletcher R. J., Gysin M., Seberry J. Application of the discrete Fourier transform to the search for generalised Legendre pairs and Hadamard matrices. Aus tralas. J. Combin., 2001, no. 23, pp. 75-86.

2. Szekeres G. Tournaments and Hadamard Matrices. Enseignement Math., 1969, no. 15, pp. 269-278.

3. Seberry J. Orthogonal Designs, Hadamard matrices, Quadratic Forms and Algebras. Springer, 2017. $476 \mathrm{p}$.

4. Schroeder M. R. (W. D.) Number Theory in Science and Communication. Berlin; New York, Springer-Verlag, 1984. Vol. 7. 350 p.

5. Moore Emily H., Pollatsek Harriet S. Difference Sets: Connecting Algebra, Combinatorics, and Geometry. Ser. Student Mathematical Library. AMS, 2013. Vol. 67. 314 p.

6. Chiarandini M., Kotsireas I. S., Koukouvinos C., Paquete L. Heuristic algorithms for Hadamard ma- trices with two circulant cores. Theoretical Computer Science, 2008, vol. 407, pp. 274-277.

7. Seberry Wallis J. Some remarks on supplementary difference sets. Colloquia Mathematica Societatis Janos Bolyai, 1973, no. 10, pp. 1503-1526.

8. Cunsheng Ding. Two constructions of $(v,(v-1) / 2$, $(v-3) / 2)$ difference families. J. Combin. Designs, 2008, no. 16, pp. 164-171.

9. Đokovic Dragomir Z., Kotsireas Ilias S. Computational methods for difference families in finite abelian groups. Spec. Matrices, 2019, no. 7, pp. 127-141.

10. Arasu K. T., Bulutoglu D. A., Hollon J. R. Legendre G-pairs and the theoretical unication of several G-array families. Combinatorics, arXiv:2004.05608v1 [math.CO], 12 Apr 2020.

11. Đokovic Dragomir Z. Survey of cyclic $(v ; r ; s ; \lambda)$ difference families with $v \leq 50$. Facta Universitatis (Nis), Ser. Math. Inform., 1997, no. 12, pp. 1-13. 
УДК 004.438

doi:10.31799/1684-8853-2021-1-2-7

Три новые длины циклических пар Лежандра

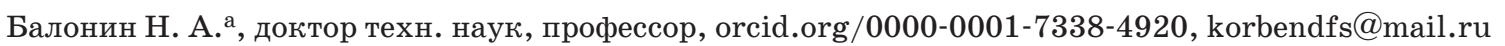
Джокович Д. Ж. ${ }^{\sigma}$, доктор наук, професcop, orcid.org/0000-0002-0176-2395, djokovic@uwaterloo.ca а Санкт-Петербургский государственный университет аэрокосмического приборостроения, Б. Морская ул., 67 , Санкт-Петербург, 190000, РФ

бУниверситет Ватерлоо, кафедра теоретической математики и Институт квантовых вычислений, Ватерлоо, Онтарио, N2L 3G1, Канада

Введение: согласно гипотезе, циклические пары Лежандра нечетной длины $>1$ всегда существуют. Такая пара состоит из двух функций $a, b: G \rightarrow Z$, принимающих значения +1 или -1 , с периодическими автокорреляционными функциями, принимающими в сумме постоянное значение -2 (исключая начальную точку). Здесь $G$ - конечная циклическая группа, $Z-$ кольцо целых чисел. Эти условия являются фундаментальными и тесно связаны со структурой бициклических матриц Адамара с двойной каймой, недостаточно полно описанной в литературе, что делает ее исследование особенно актуальным. Цель: дополнить описание бициклической конструкции с двойной каймой тремя новыми решениями пар Лежандра. Результаты: для характеристики пар Лежандра использованы подмножества $X=\{x \in G: a(x)=-1\}$ и $Y=\{x \in G: b(x)=-1\}$ из $G$. Есть 20 нечетных целых чисел $v$, меньших 200, для которых существование пар Лежандра длины $v$ не доказано. Наименьшее из них - $v=77$. Построены пары Лежандра длиной 91,93 и 123, в результате количество нерешенных случаев сократилось до 17. Приводятся примеры циклических пар Лежандра для длин $v \leq 123$. Практическая значимость: матрицы Адамара широко используются в задачах помехоустойчивого кодирования, сжатия и маскирования видеоинформации. Программы поиска матриц Адамара и библиотека построенных матриц используются в математической сети mathscinet.ru вместе с исполняемыми онлайн алгоритмами.

Ключевые слова - матрицы Адамара, периодические автокорреляционные функции, пары Лежандра, циклические матрицы, бициклические конструкции.

Для цитирования: Balonin N. A., Đoković D. Ž. Three new lengths for cyclic Legendre pairs. Информационно-управляющие системы, 2021, № 1, с. 2-7. doi:10.31799/1684-8853-2021-1-2-7

For citation: Balonin N. A., Đoković D. Ž. Three new lengths for cyclic Legendre pairs. Informatsionno-upravliaiushchie sistemy [Information and Control Systems], 2021, no. 1, pp. 2-7. doi:10.31799/1684-8853-2021-1-2-7

\section{УВАЖАЕМЫЕ АВТОРЫ!}

Научные базы данных, включая SCOPUS и Web of Science, обрабатывают данные автоматически. С одной стороны, это ускоряет процесс обработки данных, с другой - различия в транслитерации ФИО, неточные данные о месте работы, области научного знания и т. д. приводят к тому, что в базах оказывается несколько авторских страниц для одного и того же человека. В результате для всех по отдельности считаются индексы цитирования, что снижает рейтинг ученого.

Для идентификации авторов в сетях Thomson Reuters проводит регистрацию с присвоением уникального индекса (ID) для каждого из авторов научных публикаций.

Процедура получения ID бесплатна и очень проста, есть возможность провести регистрацию на 12-ти языках, включая русский (чтобы выбрать язык, кликните на зеленое поле вверху справа на стартовой странице): https://orcid.org 